\title{
SISTEM INFORMASI PEMBAGIAN KELAS SISWA BARU MENGGUNAKAN METODE K-MEANS CLUSTERING PADA SMPN 9 PALANGKA RAYA BERBASIS WEBSITE
}

\author{
Enny Dwi Oktaviyani ${ }^{\mathrm{a}, 1, *}$, Devi Karolita ${ }^{\mathrm{b}, 2}$, Licantik $^{\mathrm{c}, 3}$, Yuni Pransika ${ }^{\mathrm{d}, 4}$ \\ ${ }^{a}$ Universitas Palangka Raya, Jl. H. Timang \\ ${ }^{\mathrm{b}}$ Universitas Palangka Raya, Jl. H. Timang \\ ${ }^{\mathrm{c}}$ Universitas Palangka Raya, Jl. H. Timang \\ ${ }^{\mathrm{d}}$ Universitas Palangka Raya, Jl. H. Timang \\ 1 enny.obrien@gmail.com*; 2 devi_karolita@yahoo.com; ${ }^{3}$ herbayuli_2005@yahoo.co.id ${ }_{2}^{4}$ yunipransisca@gmail.com \\ * corresponding author
}

\section{ARTICLE INFO}

\section{Keywords}

SMPN 9 Palangka Raya

Waterfall

Class Information Sharing

System

K-means Clustering

\begin{abstract}
The information system of classroom division is a process done by Junior High School 9 Palangka Raya to divide the students into several classes. In this process schools are still using manual methods. To support the system in the division of the classes to be better, then the information system of classroom division using k-means clustering method by website based on Junior High School 9 Palangka Raya was made.

This classroom divide information system uses the waterfall method. In this method several steps to build software, namely: Requirements Definition, System and Software Design, Implementation and Unit Testing, Integration and System Testing and Operation and Maintenance. Creating a Data Flow Diagram (DFD). Entity Relationship Diagram (ERD), database design using PhpMyAdmin, User Interface design using Cascading Style Sheet, Dreamweaver and other tools to create reports.

This classroom division information testing system uses Blackbox Testing that focuses on functional requirements in software based on the software requirements specification. Management of the system that is in the form of added data, change the data, delete data and print data applied so that users can be active in this system.
\end{abstract}

\section{Pendahuluan}

\subsection{Latar Belakang}

Pembagian kelas siswa di SMP-N 9 Palangka Raya saat ini masih menggunakan sistem manual. Agar pembagian kelas dalam tiap-tiap tingkat lebih merata, maka dibutuhkan sebuah alat bantu untuk memudahkan pekerjaan dalam pembagian kelas siswa. Data yang dibutuhkan untuk pembagian kelas siswa berupa nilai akademik yang meliputi bidang studi Matematika, Bahasa Indonesia, Bahasa Inggris, dan Ilmu Pengetahuan Alam. Nilai-nilai tersebut diambil dari nilai hasil seleksi ujian tertulis pada siswa baru. Tujuan membangun sebuah sistem untuk pembagian kelas agar dapat dijadikan sebagai alat bantu untuk mempermudah admin dalan pembagian kelas siswa. Agar sistem yang akan dibangun berhasil diterapkan dengan baik, maka digunakan Kmeans untuk 
pengelompokkan secara merata berdasarkan kriteria nilai yang sudah ditentukan. Berdasarkan permasalahn tersebut, maka diusulkan "Sistem Informasi Pembagian Kelas Siswa Baru Menggunakan Metode Kmeans Clustering Pada SMP-N 9 Palangka Raya Berbasis Website” yang diharapkan dapat membantu pekerjaan sekolah dalam mengolah data dan informasi.

\subsection{Manfaat Penelitian}

Manfaat yang dapat diperoleh dari penelitian ini, yaitu :

1. Tersedianya fasilitas untuk mempermudah kinerja dalam proses penerimaan serta melakukan pembagian kelas siswa baru secara terkomputerisasi.

2. Tersedianya fasilitas yang merupakan pendaftaran online, pengumuman nilai hasil seleksi serta hasil pembagian ruang kelas

3. Melihat prosedur pendaftaran siswa baru, hasil seleksi penerimaan siswa baru serta datadata petugas dan pengajar pada SMP-Negeri 9 Palangka Raya

1.3 Landasan Teori

1. Penerimaan Siswa Baru

Penerimaan siswa baru adalah salah satu kegiatan yang pertama kali dilakukan dalam sebuah lembaga pendidikan, yang tentunya peneimaan siswa baru tersebut melalui penyeleksian yang telah ditentukan oleh pihak lembaga pendidikan kepada calon siswa baru.

2. Sistem Pendukung Keputusan

Sistem Pendukung Keputusan (SPK) atau Decision Support System (DSS) menurut Alter dalam Kusrini (2007: 15), sistem pendukung keputusan (SPK) merupakan sistem informasi interaktif yang menyediakan informasi, pemodelan, dan pemanipulasian data. Sistem itu digunakan untuk membantu pengambilan keputusan dalam situasi yang semi terstruktur dan situasi yang tidak terstruktur, dimana tak seorang pun tahu secara pasti bagaimana keputusan seharusnya

3. K-Means Clustering

Metode K-Means Clustering berusaha mengelompokkan data yang ada ke dalam beberapa kelompok, dimana data dalam satu kelompok mempunyai karakteristik yang sama satu sama lainnya dan mempunyai karakteristik yang berbeda dengan data yang ada di dalam kelompok yang lain.Dengan kata lain, metode $K$-Means Clustering bertujuan untuk meminimalisasikan fungsi objek yang diset dalam proses clustering dengan cara meminimalkan variasi antar data yang ada di dalam suatu cluster dan memaksimalkan variasi dengan data yang ada di cluster lainnya.

4. Data Flow Diagram

Saputra dan Agustin (2012:28) Data Flow Diagram atau yang disingkat DFD merupakan diagram yang menggambarkan alir data dalam suatu entitas ke sistem atau sistem ke entitas. DFD juga dapat diartikan sebagai teknik grafis yang menggambarkan alir data dan transformasi yang digunakan sebagai perjalanan data dari input atau masukan menuju keluaran atau output

a. Diagram Kontexs (Context Diagram)

Menurut (Jogiyanto,2005) Pengertian diagram konteks adalah: "Sebuah diagram sederhana yang menggambarkan hubungan antara entity luar, masukan dan keluaran dari sistem.

Diagram konteks dipresentasikan dengan lingkaran tunggal yang mewakili keseluruhan sistem."

5. Entity Relationship Diagram (ERD)

Menurut Harsiti (2012:26) Entity Relationship Diagram (ERD) adalah diagram yang menghubungkan antar entitas di dalam penyusunan/perancangan basis data. Tujuan dari Entity Relationship Diagram adalah untuk menunjukkan objek data dan relationship yang ada pada objek tersebut.

6. PHP

Menurut Simarmata (2010, 148-149) PHP adalah singkatan dari PHP Hypertext Processor. PHP mengijinkan pengembangan untuk menempelkan kode didalam HTML dengan 
menggunakan bahasa yang sama, seperti Perl dan UNIX shells. Obejk sumber tersusun sebagai halaman HTML, tetapi dengan generasi konten dinamis yang programmatic.

\section{MetodologiPenelitian}

Metodologi penelitian yang digunakan adalah sebagai berikut :

2.1 Teknik Pengumpulan Data

a. Metode Lapangan (Field Reseacrh)

Metode ini dilakukan secara langsung untuk mengumpulkan data yang berhubungan dengan SMP-Negeri 9 Palangka Raya. Data-data tersebut dikumpulkan dengan melalui beberapa cara sebagai berikut :

b. Observasi (Pengamatan Langsung)

melakukan pengamatan langsung ke tempat objek pembahasan yang ingin diperoleh yaitu melalui bagian-bagian terpenting dalam pengambilan data yang diperlukan. Pengambilan data dilakukan pada SMP-Negeri 9 Palangka Raya.

c. Interview (Wawancara)

Penulis melakukan interview (wawancara) secara langsung kepada pihak sekolah yaitu SMP-

Negeri 9 Palangka Raya untuk mendapatkan penjelasan dari permasalahan untuk dipastikan bahwa data yang diperoleh atau yang dikumpulkan benar-benar data akurat.

d. Library Research (Metode Kepustakaan)

mengumpulkan data berupa buku-buku pengetahuan dan jurnal-jurnal dari internet yang berkaitan dengan permasalahan yang diambil

2.2 Alat dan Bahan

a. Laptop dengan spesifikasi Inter(R) Core(TM) i3-2310M CPU @ $2.10 \mathrm{GHz}$ dengan RAM 2

GB serta sistem operasi yang digunakan berbasis Microsoft Windows 7

b. MySQL sebagai database server.

c. XAMMP sebagai server.

d. PHP sebagai bahasa pemrograman

e. Notepad ++ sebagai web editor

f. Microsoft Visio 2013 sebagai penggambaran desain sistem.

\subsection{Metode Pengembangan Perangkat Lunak}

Metode Pengembangan perangkat lunak yang digunakan adalah metode Waterfall menurut Sommerville (2011). Menurut Sommervile (2011) waterfall model adalah sebuah contoh dari proses perencanaan, di mana semua proses kegiatan harus terlebih dahulu direncanakan dan dijadwalkan.

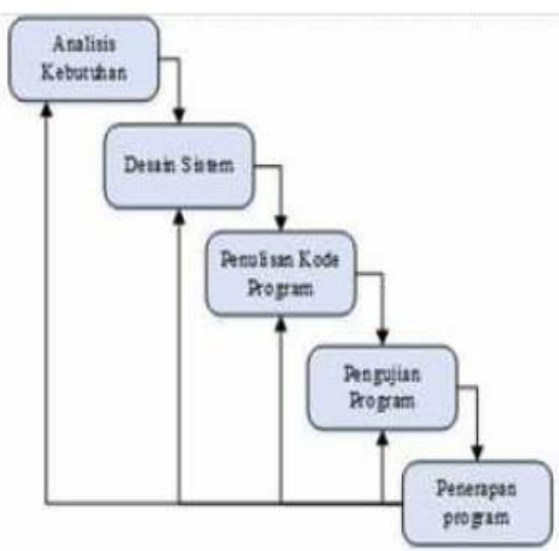


Gambar 1 Waterfall (Sommerville, 2011)

1. Analisis Kebutuhan

Mengumpulkan kebutuhan secara lengkap, kemudian dianalisis. Didefinisikan kebutuhan yang harus dipenuhi oleh program yang akan dibangun. Analisis sistem ini meliputi :

a. Analisis Teknologi

b. Analisis Pengguna

c. Analisis Sistem lama yang sedang berjalan

d. Analisis Sistem baru yang diusulkan

2. Desain

Desain dikerjakan setelah kebutuhan selesai dikumpulkan secara lengkap. Proses perancangan sistem membagi persyaratan dalam sistem perangkat keras atau perangkat lunak. Menentukan arsitektur sistem secara keseluruhan. Dalam pembuatan Sistem ini, desain menggunakan DFD (Data Flow Diagram) terdiri dari Diagram Konteks, DFD Level 0, DFD Level 1, DFD Level 2 , DFD Level 3 dan ERD (Entity Relationship Diagram).

3. Penulisan Kode

Desain program diterjemahkan kedalam kode-kode dengan menggunakan bahasa pemrograman yang sudah ditentukan. Program yang dibangun langsung diuji baik secara unit. Perancangan perangkat lunak direalisasikan sebagai serangkaian program atau unit program. Pengujian unit melibatkan verifikasi bahwa setiap unit telah memenuhi spesifikasinya. Dalam pembuatan sistem ini unit testing yang akan digunakan adalah black box testing.

4. Pengujian Program

Setelah pengkodean selesai maka akan dilakukan testing terhadap sistem yang telah dibuat. Tujuan testing adalah menemukan kesalahan-kesalahan pada sistem. Setelah pengujian sistem, perangkat lunak dikirim ke pengguna.

\section{Operation and Maintenance}

Mengoperasikan program dilingkungannya dan melakukan pemeliharaan seperti penyesuaian atau perubahan dengan situasi sebenarnya. Biasanya tahap ini merupakan fase siklus yang paling lama (meskipun tidak selalu). Sistem diinstall dan dipergunakan dengan mudah. Pemeliharaan mencakup koreksi dan berbagai kesalahan yang tidak ditemukan pada tahap-tahap sebelumnya, perbaikan atas implementasi unit sistem dan pengembangan pelayanan sistem sebagai penemuan kebutuhan baru.

\section{Hasil Dan Pembahasan}

3.1 Analisis dan Desain

Dalam desain sistem informasi pembagian ruang kelas ini menggunakan model Data Flow Diagram (DFD) adalah alat pembuatan model yang memungkinkan profesional sistem untuk menggambarkan sistem sebagai suatu jaringan proses fungsional yang dihubungkan satu sama lain dengan alir data baik secara manual maupun komputerisasi. DFD ini sering disebut juga dengan nama Bubble Chart atau diagram, model proses, diagram alur kerja atau model fungsi. Tahap tahap pembuatan desain website yang dibuat adalah sebagai berikut : Diagram konteks sistem ini dapat dilihat pada gambar 2 ini. 


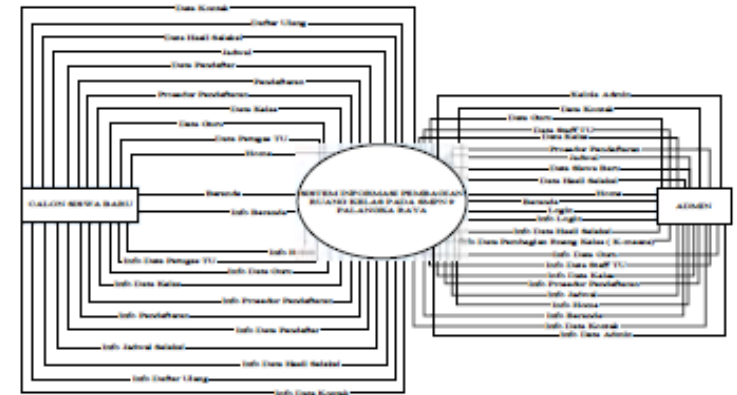

Gambar 2 Diagram Konteks

Penggambaran sistem DFD level-1 pada sistem ini dapat dilihat pada gambar 3

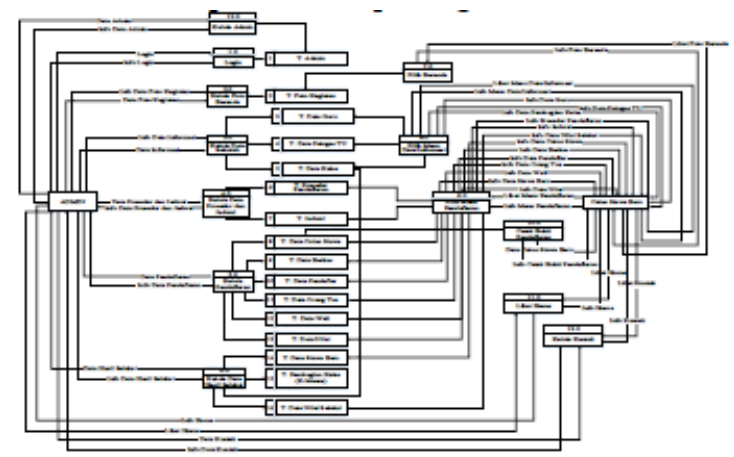

Gambar 3. DFD Level 1

Entity Relationship Diagram (ERD) digunakan untuk membangun basis data untuk hubungan dari dua atau lebih entitas/tabel,

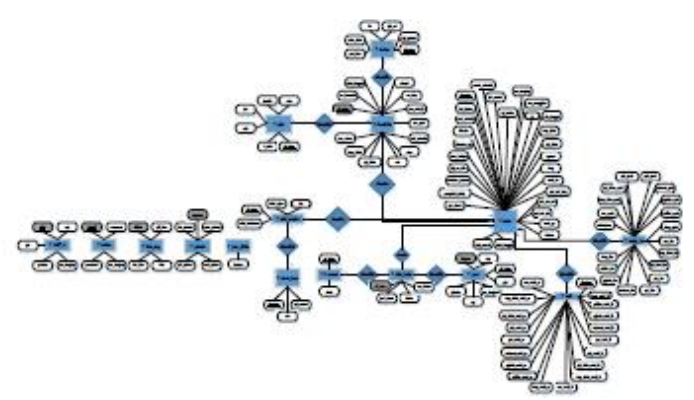

Gambar 4. ERD

Setelah melewati tahap analisa dan desain program maka selanjutnya rancangan desain yang telah dibuat dimplementasikan ke dalam koding program. Kemudian dilakukan tahap pengujian program Implementasi merupakan tahap sistem siap dioperasikan pada keadaan yang sebenarnya, sehingga akan diketahui apakah sistem yang telah dibuat telah menghasilkan tujuan yang diinginkan. Implementasi perangkat lunak sistem informasi meliputi alasan pemilihan perangkat lunak, batasan implementasi, lingkungan implementasi yaitu lingkungan perangkat keras dan lingkungan website, dan hasil implementasi. Program yang digunakan dalam implementasi website Sistem Informasi Pembagian Ruang Kelas Siswa Baru Menggunakan Metode K-Means Clustering ialah browser Mozilla Firefox hampir dapat memanfaatkan seluruh kemudahan dan kecanggihan yang dimiliki oleh sistem operasi Windows. 


\section{JURNAL TEKNOLOGI INFORMASI}

[E-ISSN 2656-0321]

[Vol. 12 No. 2]

Jurnal Keilmunan dân Aplikasi Bitang Teknik Informaiika

\subsection{Implementasi Halaman Login}

Halaman ini merupakan halaman untuk menampilkan menu login, admin diharuskan mengisi atau diwajibkan menginput data seperti username dan password terlebih dahulu sebelum masuk ke bagian halaman utama program

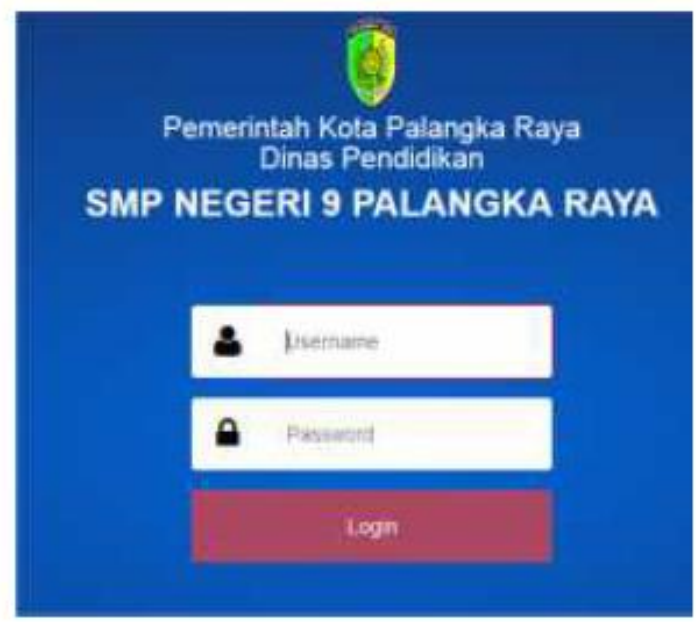

Gambar 5. Halaman Login

\subsection{Implementasi Halaman Home Admin}

Halaman ini menunjukkan bagian terpenting program yakni halaman utama program. Halaman Home ini terdiri dari beberapa menu yang tersedia yaitu manajemen beranda, data sekolah, prosedur dan jadwal, pendaftaran, data hasil seleksi, ubah password dan kelola kontak. Admin bertugas untuk mengelola data kemudian akan diolah oleh sistem dan selanjutnya akan didapatkan hasil sesuai dengan apa yang diputuskan.

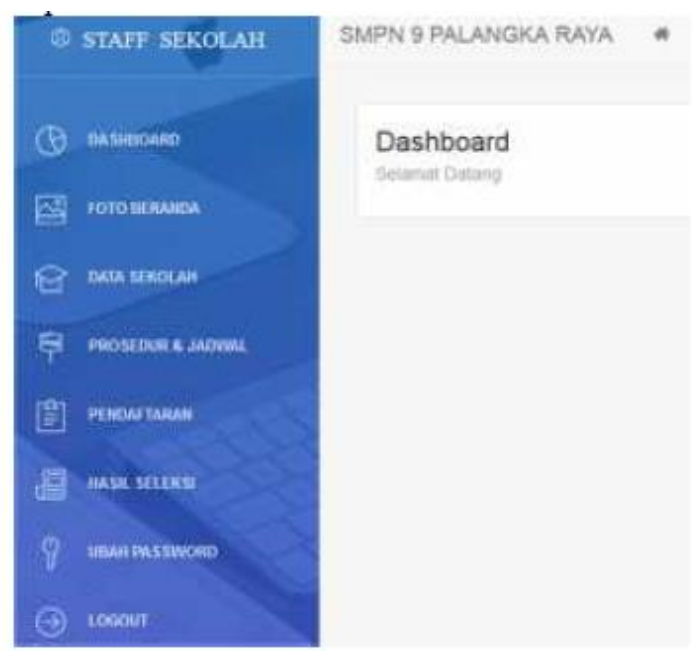

Gambar 6. Halaman Home Admin

\subsection{Halaman Beranda Admin}

Dibawah ini merupakan halaman beranda yang dikelola oleh admin. Dimana data beranda ini berupa foto-foto kegiatan yang ada di sekolah. Terdapat 2 aksi yang dapat dilakukan oleh admin yaitu tambah dan hapus data. 


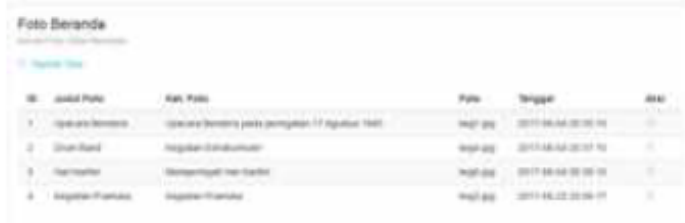

Gambar 7. Halaman Beranda Admin

\subsection{Halaman Data Guru}

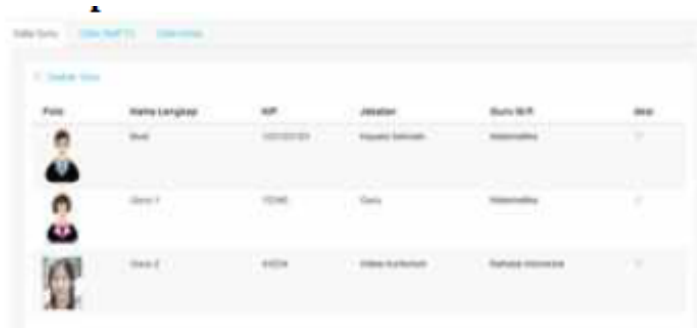

Gambar 8. Halaman Data Guru

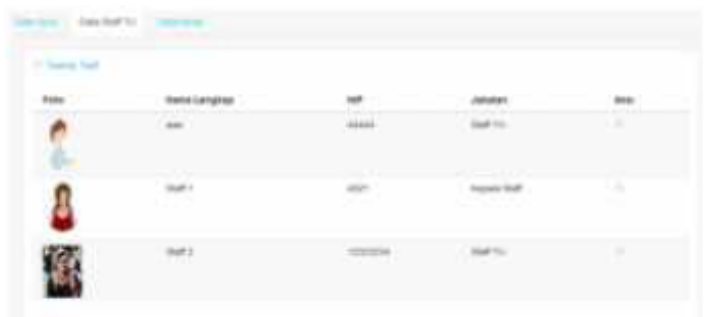

Gambar 9. Halaman Data Staff TU

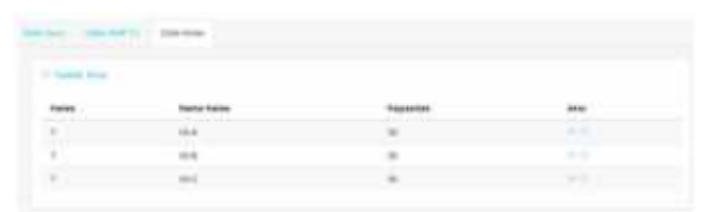

Gambar 10. Halaman Data Kelas

3.6 Halaman Prosedur Pendaftaran

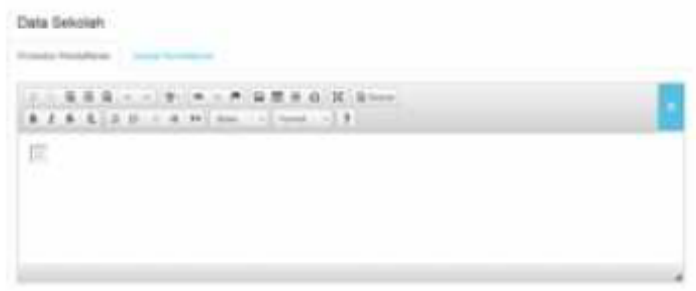

Gambar 11. Halaman Prosedur Pendaftaran 
[E-ISSN 2656-0321]

[Vol. 12 No. 2]

[Agustus 2018]

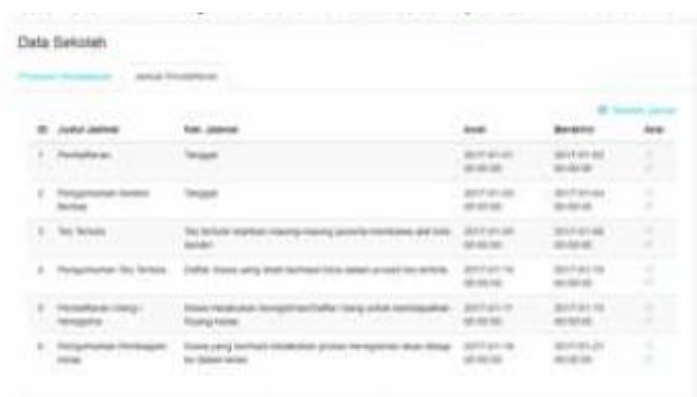

Gambar 12. Halaman Data Jadwal

3.7 Halaman Pendaftaran

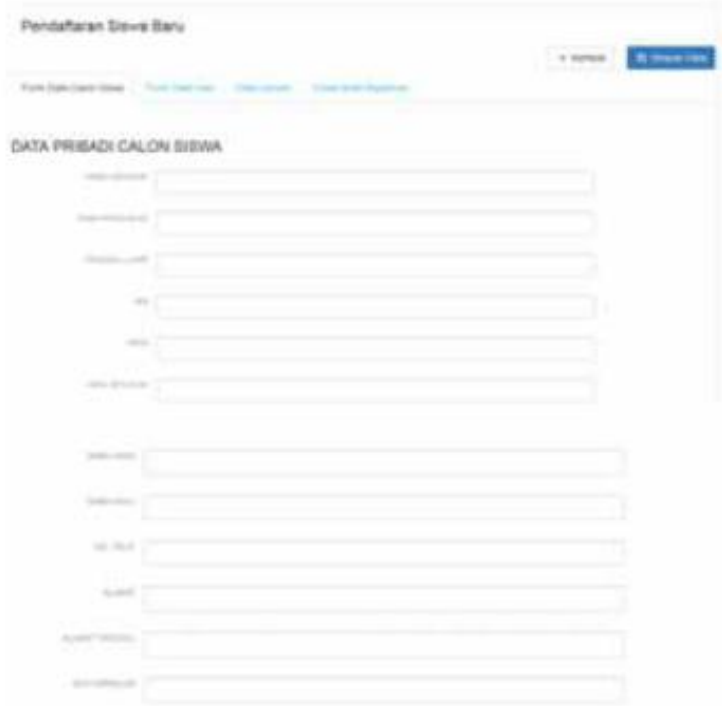

Gambar 13 Halaman Data Calon Siswa

3.8 Halaman Pendaftaran Ulang

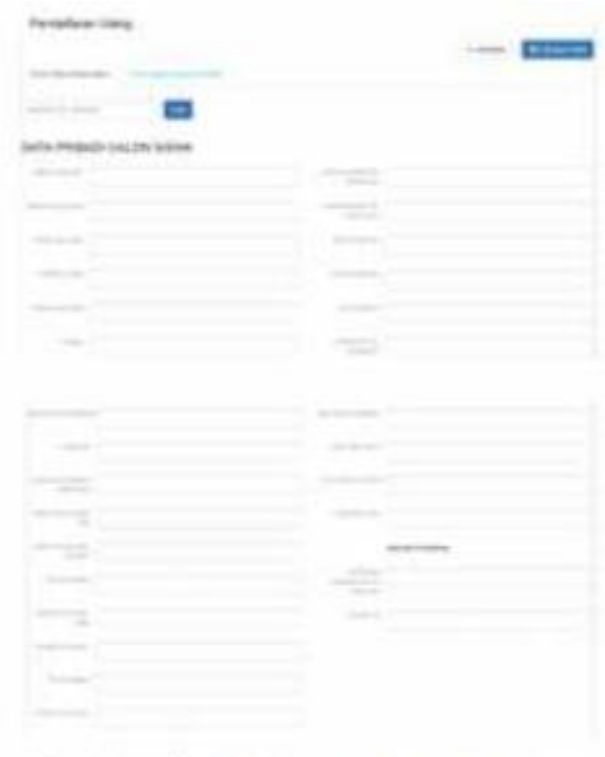


Gambar 14. Halaman Data Siswa Baru

3.9 Halaman Hasil Seleksi

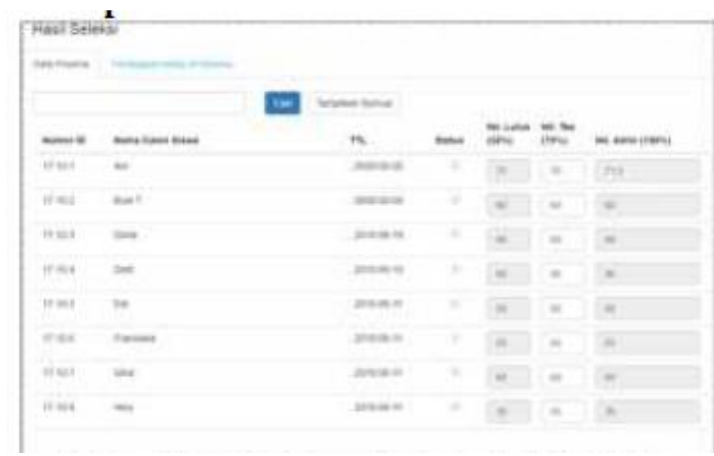

Gambar 15. Halaman Data Peserta Pendaftaran

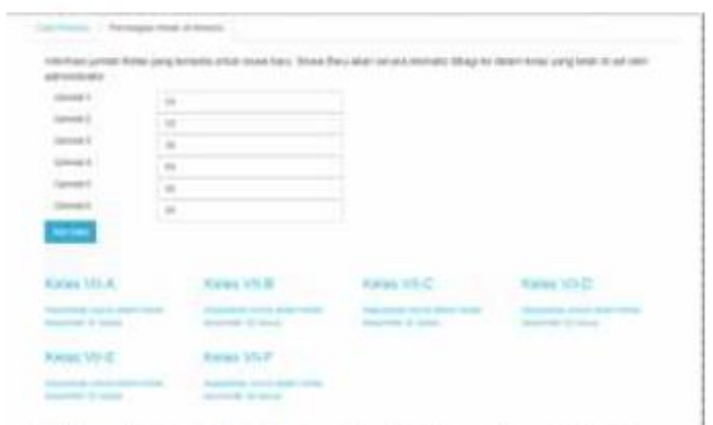

Gambar 16. Halaman Data Pembagian Ruang Kelas

3.10 Halaman Kelola Kontak

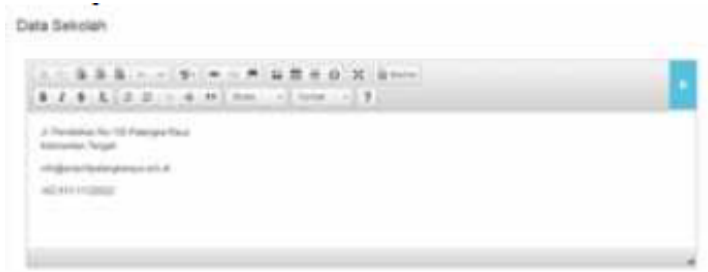

Gambar 17. Halaman Kelola Kontak

3.11 Halaman Kelola Password

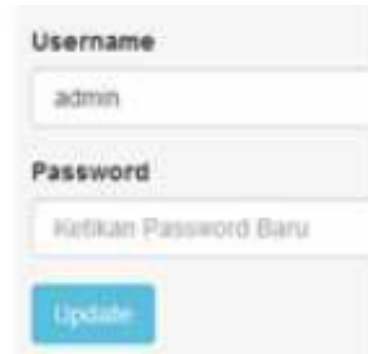

Gambar 18. Halaman Data Ubah Pasword 


\section{Kesimpulan}

4.1 Kesimpulan

Setelah dibuatnya Sistem Informasi Pembagian Kelas Siswa Baru Menggunakan Metode $K$-means Clustering pada SMPN 9 Palangka Raya Berbasis Website, maka proses pembagian kelas dapat dilakukan pada sistem tanpa harus melakukan pembagian dipembukuan. Dengan adanya rancangan pembagian menggunakan metode $k$-means clustering ini memungkinkan untuk pembagian siswa secara merata kedalam kelas berdasarkan nilai yang dimiliki oleh siswa baru.

Penelitian ini menggunakan data siswa baru yang berjumlah 30 orang yang telah dinyatakan lulus seleksi. Dengan menggunakan metode $k$-means clustering pada aplikasi Sistem Informasi Pembagian Kelas Siswa Baru Menggunakan Metode K-means Clustering pada SMPN 9 Palangka Raya Berbasis Website dan dengan didapatkan hasil pembagian siswa dengan jumlah 9 menempati kelas $\mathrm{A}$, siswa dengan jumlah 2 menempati kelas $\mathrm{B}$, siswa dengan jumlah 3 menempati kelas $\mathrm{C}$, siswa dengan jumlah 5 menempati kelas $\mathrm{D}$, siswa dengan jumlah 4 menempati kelas E, siswa dengan jumlah 7 menempati kelas F.

a. Saran

Hasil dari pengelompokkan menggunakan metode ini akan menghasilkan jumlah siswa yang berbeda pada setiap kelas. Adapun jumlah siswa menjadi tidak seimbang maka penyusun menyarankan bagi peneliti yang ingin menggunakan metode ini untuk mengelompokkan suatu data disarankan menggunakan data yang lebih banyak agar jumlah data yang dihasilkan seimbang dalam suatu kelompok ( misalnya dalam satu kelas jumlah siswa yang ditempatkan tidak jauh berbeda dari jumlah siswa yang ditempatkan dikelas lain).

\section{Daftar Pustaka}

[1] Dr. Suyanto, ST., M.Sc. 2008. Data Mining Untuk Klasifikasi dan Klasterisasi Data.Bandung:Informatika

[2] Fathansyah. 2012. Basis Data. Bandung: Informatika

[3] Jogiyanto.2012. Pengantar Sistem Informasi. Yogyakarta : Andi

[4] Kadir, Abdul. Pengenalan Sistem Informasi. Yogyakarta:Andi

[5] Sommerville, Ian. 2011. Software Engineering (REkayasa Perangkat Lunak). Jakarta: Erlangga.

[6] Sutabri, Tata. 2012. Analisis Sistem Informasi. Yogyakarta:Andi

[7] Sutarman.2012.Pengantar Sistem Informasi.Jakarta:Bumi Aksara. 